\title{
Система государственных веб-ресурсов в Республике Абхазия: проблемы информационного поля
}

Аннотация: Интернет пространство в современном мире является обязательной составляющей практически любого явления и события. Все самое важное, интересное, актуальное находит свое отражение в глобальной сети. Быть представленным в виртуальном пространстве - это значит быть в состоянии заявить о себе. Республика Абхазия, государство со сложным политическим статусом, на данный момент является полноценно представленным только в интернет-пространстве, поскольку большинство стран мирового сообщества рассматривают регион, как территорию аннексированную у Грузии. В статье будет подробно проанализировано развитие официальных государственных веб-ресурсов республики, проблемы наполненности информационного поля, сложности развития виртуального сектора, отсутствие своего национального домена верхнего уровня, причины отсталости в развитии негосударственных веб-ресурсов. В качестве методики анализа сайта автор статьи использует свои исследовательские разработки и европейские программы улучшения качества электронных ресурсов по культуре и этнографии.

Review: Nowadays the Internet space is an essential element of practically all phenomena or events. Everything important, interesting and topical is embodied in the global network. To be presented in the virtual space means to be able to show that you are important. The Republic of Abkhazia, the state that has a rather complicated political status, is fully presented only in the Internet space today because the greater part of the global community considers the region to be the territory that has been annexed from Georgia. The author of this research article analyzes the process of development of official state web-resources of the republic, the issues related to completing the content of the information space, difficulties faced in the development of the virtual sector, absence of the national domain of the highest level and causes of particular gaps in the development of non-state web-resources. As the main method for analyzing the website, the author of the article uses her own research developments as well as European programs on improving electronic resources in the sphere of culture and ethnography.

Ключевые слова: виртуальное пространство, этнополитика, Абхазия, информационное поле, информационная безопасность, веб-ресурсы, самоидентификация, этническая идентичность, виртуальная идентичность, государственные сайты.

Keywords: virtual space, ethnopolitics, Abkhazia, information space, information security, web-resources, self-identification, ethnic identity, virtual identity, state websites.

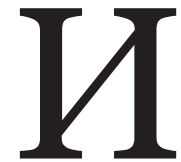

нтернет пространство в современном мире является обязательной составляющей практически любого явления и события. Все самое важное, интересное, актуальное находит свое отражение в глобальной сети Интернет. Быть представленным в виртуальном пространстве - это значит быть в состоянии заявить о себе. Сейчас уже практически немыслимы экономические, культурные, социальные, политические новшества, которые бы не были отражены на веб-ресурсах. Это является очевидной составляющей все- го, что происходит в современном публичной сфере. Каждое государство, каждая этническая группа так же осваивает виртуальное пространство на разных уровнях.

Репрезентация в глобальной сети для суверенного государства и нации является одним из негласных обязательных аспектов, в том числе и самоидентификации, это во многом основа информационной парадигмы.

Республика Абхазия, государство со сложным политическим статусом, на данный момент является полноценно пред- 
ставленным только в интернет-пространстве. Поскольку Абхазия была признана рядом стран, но большая часть государств считает Республику аннексированной территорией у Грузии, то международная политическая активность региона невелика. Интернет же дает возможность транслировать внутренние аспекты развития государства для всего заинтересованного мирового сообщества.

На государственном уровне в Республике Абхазия достаточно давно существует понимание необходимости создания собственных сайтов и информационных порталов. Посчитать, даже количественно, все сайты, связанные с Абхазией, на данный момент достаточно проблематично, но стоит отметить, что их уже более тысячи. Условно, можно разделить веб-ресурсы на официальные, поддерживаемые Президентом и правительством, и неофициальные частные инициативы. В данной статье мы уделим основное внимание именно системе официальных государственных сайтов, как наиболее развитой в республике.

Удельная доля официальных интернет-ресурсов в республике очень велика, что может свидетельствовать не столько о глобальном вмешательстве государственных структур в виртуальное пространство, сколько о недостаточно большом количестве альтернативных сайтов. Согласно оценкам экспертов из администрации Президента Абхазии на 2011 год, количество активных пользователей сети в республике по оптимистичным подсчетам составляет около 20000 человек. Создавать и развивать частные сайты практически невыгодно и в этом нет особой заинтересованности. Наиболее активная часть пользователей молодежь, «сидит» в российских и международных глобальных сетях: Вконтакте, Одноклассники, Живой журнал, реже Фейсбук. Общение в социальных сетях практически полностью покрывают частную потребность использования Интернета.

Созданием государственной системы веб-ресурсов занимался при президенте С.Багапше специальный Сектор информации и аналитики в структуре отдела внутренней политики Администрации Президента. Сектор функционировал до 2011 года и закончил свою работу в связи со смертью С.Багапша. Вплоть до 2011 года существовал ряд программ по развитию информационного пространства Абхазии в виртуальном пространстве, в том числе общая информационная база паспортов, правительственные сайты, информационные базы МВД, таможни. Финансирование создания сайтов и поддержки информационного наполнения осуществлялось из бюджета республики. Свой сайт должны были создать все государственные учреждения. Процедура создания сайтов была прописана и регулируема: каждое государственное подразделение могло подать служебную записку о необходимости выделения бюджетных средств на создание сайта, служебная записка поступала на рассмотрение в Аппарат Президента и подписывалась президентом, далее смета утверждалась через Министерство финансов. По информации, предоставленной компетентными источниками, практически все существующие на данный момент официальные государственные сайты были созданы до 2011 года именно по этой программе.

Официальные сайты Республики Абхазии аналитический портал polpred.com разделяет на следующие тематические группы: экономика, армия и безопасность, внешняя торговля, законодательство, книги, культура, политика, СМИ, таможня, туризм и виза.

Если разобрать каждый из разделов подробней, то классификация сайтов в структуре портала представляется достаточно условной, а иногда и сомнительной. В раздел экономики включен сайт Кабинета министров Республики Абхазия; в разделе «внешняя торговля», наравне с сайтами Торгово-промышленной палаты, Торгового представительства РФ в Республике Абхазия присутствуют сайты Посольства РФ в Абхазии, Посольства Республики Абхазия в РФ; особую неоднозначность эта типологизация приобретает тогда, когда ссылка на Сайт кабинета министров, приводит на страницу с рекламным объявлением о продаже современного коммуникатора от известного производителя. Раздел «Армия и безопасность», в котором расположена ссылка на сайт Министерства внутренних дел Республики Абхазия является одним из наиболее логичных.

В разделе «Культура» обозначен только один ресурс - Министерство культуры республики. В политическом разделе - ка- 
талог правительственных сайтов и сайт Министерства иностранных дел. Каталог правительственных сайтов имеет англоязычный вариант, в нем представлено всего 12 активных ссылок, две из которых на электронную энциклопедию Википедия, одна на результаты по поисковому слову «Абхазия» в Yahoo, на Абхазский институт социальных и экономических исследований, сборник статей посвященный взаимодействию грузин и абхазцев. Некоторые ресурсы представлены с перенаправленной гиперссылкой. В целом, стоит отметить нелогичную выборку ресурсов, без определенного критерия отбора и классификации. То, что заявлено в качестве Каталога правительственных сайтов, не соответствует по содержанию этому названию, как таковому.

Прежде чем перейти к анализу непосредственно сайтов, стоит сказать о методике анализа ресурса с этнической тематикой , опробованной автором статьи ${ }^{1}$.

Большой интерес по обозначенной тематике представляет документ «Брюссельская структура качества» (Brussels Quality Framework) ${ }^{2}$. Этот документ лег в основу деятельности рабочей группы «Определение потребностей пользователей, содержания и критериев качества веб-сайтов по культуре». Разработка методик и рекомендаций по улучшению информативного и структурного качества сайтов осуществлялась в рамках проекта «Минерва». Итоговыми документами рабочей группы стали: руководство «Повышение качества для граждан Европы» 3 и руководство «Принципы качества вебсайтов по культуре» ${ }^{4}$, так же представленное и на русском языке 5 .

\footnotetext{
1 Лапкина H.A. Социальный потенциал интернет-ресурсов в дискурсе этничности // Ученые записки Петрозаводского государственного университета. Сер. «Общественные и гуманитарные науки». № 3 (116). Май, 2011. С. 73-76.

2 «Брюссельская структура качества» Brussels Quality Framework http://www.w3c.it/papers/cultureAcrossCultures.pdf

${ }^{3}$ Handbook for quality in cultural Web sites: improving quality for citizens

http://www.minervaeurope.org/publications / qualitycriteria1_1draft/qualitypdf_1003.pdf

${ }^{4}$ Quality Principles for cultural Web sites: a handbook http://www.minervaeurope.org/publications/qualitycommentary/qualitycommentaryo50314final.pdf 5 Принципы качества веб-сайтов по культуре http://www.minervaplus.ru/docums/1oprncp.htm
}

Рассмотрим эту программу подробней, поскольку она единственная разработана для веб-ресурсов по культуре, а, соответственно, этнология и этническая тематика являются их неотъемлемой частью. Сайты, посвященные культуре, в большей степени способны повлиять на формирование этнических установок, стереотипов, предубеждений. Именно сайты с этнической тематикой формируют в виртуальном пространстве самоидентификацию небольших народностей и культур.

Программа призвана повысить качество онлайновой информации о культуре. По мнению автора, внедрение принципов толерантности, взаимоуважения культур, поликультурности в пространство Интернет так же относится к способам повышения качества информации. Не только пропаганда терпимости, но и демонстрация в «цифровой культуре» этнического многообразия может способствовать формированию общеевропейского пространства как пространства толерантного, способного понять и принять существование других народов, обычаев, традиций. Информационное наполнение госу-

дарственных официальных сайтов дает представление о политическом образовании, культурной и социальной идентичности региона.

Для оценки Интернет-ресурсов по культуре были разработаны Десять принципов качества 6 .

1. прозрачность. На сайте должна быть ясно и открыто обозначена цель его создания, назначение, организация, обслуживание сайта.

2. эффективность. Оценка и релевантность информации, наличие комментариев и пояснений, простоту навигации по материалу.

3. поддержка ресурса. Своевременное и надлежащее обслуживание, регулярная актуализация части содержания (новости, живое общение), своевременное обновление информации, внимание к оформлению, создание архива, создание регулярных технических копий.

4. доступность. Ориентация на обслуживание широкого круга пользователей, в независимости от их физических

6 Принципы качества веб-сайтов по культуре http://www.minervaplus.ru/docums/1oprncp.htm 
ограничений или используемых технологий. Внимание к визуальному интерфейсу, работа в разных типах браузеров, универсализация доступа.

5. ориентация на пользователя. Учет потребностей пользователей, простота работы с ресурсом, обратная связь, вовлечение в организацию сайта, удобство интерфейса, навигация, консультации с целевой аудиторией.

6. реактивность. Живое общение, онлайн диалог с пользователями, способность отвечать на вопросы и предложения пользователей, интерактивность, разработка процедур по анализу представленной информации, поддержание высокого авторитета на национальном уровне.

7. многоязычность. Обеспечение минимального уровня доступа к материалом более, чем на одном языке. Устранение языкового барьера, включение не только европейских языков (языки иммигрантов), отражение в многоязычности официальной политика.

8. совместимость. Связь с другими вебсайтами по культуре, с порталами по культуре, обмен информацией с другими сайтами, совместимость в стандартах веб-технологий и языке программирования, прозрачность специализации, система поиска по сайту.

9. управляемость. Условия использования содержания сайта, управление правами интеллектуальной собственности, защита от вмешательства в частную жизнь, этические и юридические аспекты работы Интернет-ресурса.

10. сохранность. Использование стратегий и стандартов, обеспечивающих долговременную сохранность содержания сайта: архивирование, создание резервных копий, миграция на новые носители.

При анализе сайта по каждому из принципов предоставляется краткая характеристика понятия, комментарии по обоснованию необходимости использования данного принципа, критерии оценки работы сайта согласно представленному принципу, точный перечень контрольных характеристик для оценки сайта и практические тесты, позволяющие характеризовать уровень сайта. Для работы с представленной системой оценки разработчики рекомен- дуют последовательно оценить веб-сайт на соответствие каждому из указанных принципов. Определенным достоинством этой системы оценки является маневренность принципов, гибкая матрица приоритетов. «Значение принципов может меняться в зависимости от жизненного цикла проекта - некоторые принципы особенно важны на этапе планирования проекта, а значение других возрастает по мере его завершения »7. Для анализа веб-сайта необходимо, прежде всего, понять, как можно применить каждый конкретный принцип именно к анализируемому ресурсу. При работе с каждым принципом проводить критический анализ набора критериев и, учитывая особенности сайта, вносить в них при необходимости изменения. После заполнения перечня контрольных характеристик и выполнения тестов, следует повторно проанализировать сайт с целью определения мер по повышению его качества. Сам принцип работы с системой предусматривает возможность развития и самосовершенствования подхода.

При анализе сайта также очень важен учет взаимосвязи между различными стадиями жизненного цикла ресурса и десятью принципами качества. Для каждой стадии определяются свои наиболее важные принципы. В программе выделены следующие стадии жизненного цикла сайта: планирование веб-сайта, его организация, отбор содержания, процесс оцифровки, хранение и сохранность цифрового эталонного материала, сбор метаданных, внедрение веб-сайта, размещение в онлайн, постоянная техническая поддержка. Существует матрица пар «принцип - стадия» устанавливающая уровень приоритетности, что так же следует учитывать при проведении анализа ресурса ${ }^{8}$.

Поскольку цифровое информационное поле Республики Абхазия развивается не так давно, то, согласно информации, полученной от сотрудников Сектора информации и аналитики в ходе личных интервью с автором статьи, стадии планирования, ор-

\footnotetext{
7 Принципы качества веб-сайтов по культуре http://www.minervaplus.ru/docums/1oprncp.htm

${ }^{8}$ Н.A. Лапкина Методики анализа дискурса этничности в глобальной сети // Исторические, философские, политические и юридические науки, культурология и искусствоведение. Вопросы теории и практики, № 4 (10) 2011. Часть 1, С. $92-96$
} 
ганизации, отбора содержания и сбора данных происходили в очень сжатые сроки, на многих ресурсах часть информации дублируется, как например, история Абхазии и основные государственные характеристики.

В связи с тем, что большинство государственных сайтов было создано в рамках общей программы, то их дизайн и структура очень похожи. Исключением является сайт Президента, и сайты, появившиеся после 2011 года, когда официально была завершена работа Сектора.

Анализируя сайты, сразу же стоит отметить достаточно скромный и лаконичный дизайн этих ресурсов в целом, что является свидетельством реализации задачи репрезентации в сети, как самоцели. Современные технологии и массмедийное пространство это прежде всего виртуальное присутствие объекта, его представленность на сайтах, в социальных сетях. Если государство, явление, политик, отрасль не задействована в интернете, то это в современном мире накладывает отпечаток определенной отсталости и неразвитости, в связи с чем, любые значимые, а особенно государственные и официальные явления должны быть виртуализированы.

Для более подробного анализа мы взяли сайт Парламента Республики Абхазия www. parlamentza.org и сайт Министерства культуры Республики Абхазия mkra.org

Заходя на сайт Парламента Республики Абхазия с поисковой системы, отмечаем максимальную лаконичность дизайна, точнее полное его отсутствие, оформление в виде новостной ленты, похожей на электронный вариант официального бланка организации. При более детальном рассмотрении, сайт оказывается реализован в нескольких версиях: полная, PDA версия и контрастная. Именно PDA-версия и открывается при переходе на сайт через поисковые системы. Контрастная версия - это версия в черно-белом варианте, что встречается достаточно редко.

В версии PDA верхнее и нижнее меню идентичны, все разделы имеет подразделы, часть из которых не открывается из-за программных ошибок. Наполненность сайта осуществлена во многом нормативными документами: Регламент Народного собрания - Парламента Республики Абхазия, Положение об Аппарате Народного Coбрания, Конституция Республики Абхазия и др. В целом стоит отметить тот факт, что основную часть контента большинства государственных сайтов составляют именно нормативные документы, динамичная новостная лента с событиями и мероприятиями реализована значительно слабее.

В целом, не смотря на ошибки программного характера, структура сайта выверенная и удобная: Главная, Республика Абхазия, Состав и структура, Новости, Документа, Обращения, Контакты. Структура сайта минималистична, но при этом абсолютно функциональна. Стоит отдельно отметить интерактивную составляющую веб-ресурса - раздел Обращения, в котором существует форма для электронных обращений, порядок и время приема граждан.

Полная версия сайта не открывается через поисковые системы, но открывается уже на самом сайте. Полная версия выглядит очень представительно, соблюден баланс между эстетичным дизайнерским оформлением и официальным характером ресурса. Сайт сделан очень эргономично, удобно, на хорошем уровне. Стоит отдельно отметить, что контент всех официальных сайтов выверен, нет сомнительных или провокационных материалов.

Интересным с точки зрения контекста и представления именно этнической и культурной самоидентичности в официальном порядке является сайт Министерства культуры Республики Абхазия mkra.org

Как и все официальные сайты, сайт Минкультуры выполнен в достаточно лаконичном дизайне, имеет в качестве контента массив нормативных документов. Интересным является то, что раздел “Министерство" вынесен отдельно, в нем обращение Министра к посетителям сайта, раздел со всеми экс-министрами и краткой справкой о каждом. Представлены видные деятели культуры, градация почетных званий и правительственных наград, с именными списками. Это дает ресурсу адресное, личное обращение к пользователям, делает контент не официально-сухим, но достаточно интересным для чтения более широкому кругу посетителей. Очень хорошо на сайте представлен раздел “Мультимедиа”, с подразделами фото галерея, видеоархив, аудио архив. Эти подразделы продублированы в правой колонке в структуре сайта. Стоит отметить хорошую наполненность этих подразделов, а так же качество наполнения: прекрасное звучание аудиозаписей, профессиональный монтаж и компоновку 
видеосюжетов, высокий художественный уровень большинства фотографий.

Активна новостная лента в разделе Coбытия, в среднем по 4-5 крупных мероприятий каждый месяц. В разделе ссылок на другие ресурсы, есть ссылка на Абхазскую интернет-библиотеку, где самым первым тематическим разделом обозначены: история, этнография Абхазии, археология. В разделе представлен значительный список литературы, все ссылки активны и ведут к полным текстам публикаций.

В целом, сайт Министерства культуры один из лучших официальных ресурсов по таким критериям, как поддержка, доступность и ориентация на пользователя, прозрачность и эффективность. Сайт соответствует и критериям реактивности, поскольку существует раздел “Обращения”, где посетитель может задать любой вопрос, используя электронную форму. Данный ресурс максимально включен в глобальное виртуальное пространство, поскольку имеет отдельную группу на Фейсбуке, что сейчас стало уже “хорошим тоном" в формате присутствия в Сети.

При достаточно хорошей структуре официальных веб-ресурсов, стоит отметить, что количественно посещаемость не столь велика, но это связано с общей удельной массой потенциальных пользователей. Большинство сайтов представлены только на одном языке - русском, нет версий на других иностранных языках. Сайт Министерства иностранных дел, выгодно отличается от большинства других именно наличием версий на иностранных языках. Существует версия сайта на абхазском языке, тогда как большинство даже государственных веб-ресурсов представлены только на русском (сайт Министерства культуры, сайт Парламента Республики Абхазия, Министерство внутренних дел, сайты основных СМИ). Среди сайтов у которых существует версии на иностранных языках и на абхазском можно отметить сайт Торгово-промышленной палаты Республики Абхазия.

О слабом развитии интернет-пространства Абхазии говорит тот факт, что у страны нет своего национального домена верхнего уровня (country code Top-Level Domain (ccTLD)), что подчеркивает и спорный политический статус республики. Bсе сайты располагаются в зоне .ru, .com, .org, .info.
Как сообщает источник, переговоры о выделении Абхазии собственной площадки с доменным статусом велись, но были неуспешны, поскольку регистрация национальных доменов первого уровня связана с определенными условиями, одно из которых - это признание страны на международной арене. Значительным для внутренней безопасности республики является тот факт, что практически вся внутренняя правительственная переписка ведется на mail.ru , что влечет за собой значительную утечку информации. Перевести переписку на другие почтовые серверы не удалось, вопрос был закрыт так же в 2011 году. Как уже было сказано, развитие частных сайтов в республике крайне низкое, даже в области туризма и экономики.

Модули большинства сайтов достаточно простые и прозрачные, нет сложных структурно выполненных ресурсов, тоже можно сказать и о дизайне большинства из них.

Если обратиться к количественным показателям, то одним из наиболее посещаемых, согласно принятой рейтинговой системе, является сайт www.apsny.ru - за ним, с небольшим отставанием, следует www.abhazia.com - около 1200 посещений в день, и около 800 посещений в день соответственно. Все остальные ресурсы имеют посещаемость на порядок ниже. Количественный показатель в данном случае является прямым свидетельством распространения Интернета на территории республики вообще.

Незначительный, но заметный на общем фоне, сегмент интернет-ресурсов - это сайты о туризме. Что соответственно является определенным маркером вектора экономического развития региона. Общим моментом практически для всех туристических сайтов является представление развернутой информационной справки о Республике, причем формат данного информативного блока выдержан в максимально лаконичных и приближенных к официальным государственным.

Большинство коммерческих туристических отраслей не заинтересованы в создании собственных сайтов. Существующие в большом количестве гостиницы практически не обладают представленным контентом в сети, как сообщает источник, руководство гостиниц не заинтересовано в выделении средств на создание сайта, по- 
скольку считает, что “те, кто хочет остановится в гостинице, и так ее найдут”.

Немногие коммерческие структуры имеют свой сайт, те же кто хотел его создать, так же обращались к специалистам из Сектора информации и аналитики отдела внутренней политики Администрации Президента, так, например, был создан сайт одного из Винзаводов Абхазии. Вплоть до 2011 года все специалисты в области информационных интернет технологий и все веб-дизайнеры были из России и Украины, только к 2013 году стали появляться сайты созданные непосредственно абхазскими специалистами, эти сайты пока на самых простых движках и с самым простым административным решением. При президенте С. Багапше существовал проект о централизованном привлечении программистов фрилансеров из России и Украины с целью развития информационного пространства, проект был свернут сразу же после смерти С.Багапша.

В ходе обзорного исследования сайтов был выявлен ряд казусов, например, активная ссылка на Сайт Кабинета министров Республики Абхазии ведет на страницу с рекламой Айфона пятой серии, причем ссылки расположены на официальных ресурсах: сайт Президента Абхазии, сайт polpred.com

На данный момент можно отметить практически пустое информационное поле, развитием и обновлением ресурсов не занимаются централизовано, при отсутствии государственной поддержки развитие абхазского виртуального пространства практически остановилось. Наиболее активная часть пользователей находится в социальных сетях, что не создает культурно-информационного контекста, отражающего именно особенности абхазского региона.

В качестве необходимых векторов развития информационного поля республики Абхазия, можно выделить следующие: продолжение ведения переговоров о получении своего национального домена первого уровня, перевод большинства ресурсов на европейские языки, создание активного, “живого" информационного поля государства, развитие ресурсов неофициального сектора. Развитие данных направлений очень важно именно для Абхазии, поскольку виртуальная представленность может способствовать увеличению политического веса государства на мировой арене.

\section{Исследование выполнено при поддержке РГНФ проект № 11-о6-о1177а}

\section{Список литературы:}

1. Исследование выполнено при поддержке РГНФ проект № 11-о6-01177а

2. Лапкина Н.А. Социальный потенциал интернет-ресурсов в дискурсе этничности // Ученые записки Петрозаводского государственного университета. Сер. «Общественные и гуманитарные науки». № 3 (116). Май, 2011. С. 73-76.

3. Brussels Quality Framework // http://www.w3c.it/papers/cultureAcrossCultures.pdf

4. Handbook for quality in cultural Web sites: improving quality for citizens // http://www.minervaeurope.org/publications/qualitycriteria1_1draft/qualitypdf_1003.pdf

5. Quality Principles for cultural Web sites: a handbook // http://www.minervaeurope.org/publications/qualitycommentary/qualitycommentaryo50314final.pdf

6. Принципы качества веб-сайтов по культуре // http://www.minervaplus.ru/docums/1oprncp.htm

7. Н.А. Лапкина Методики анализа дискурса этничности в глобальной сети // Исторические, философские, политические и юридические науки, культурология и искусствоведение. Вопросы теории и практики, № 4 (10) 2011. Часть 1, С. 92-96

8. Ярлыкапов А.А. Современный Дагестан: актуальные этнополитические и этноконфессиональные проблемы // NB: Проблемы общества и политики. - 2012. - 3. - C. 130-153. DOI: 10.7256/2306-0158.2012.3.257. URL: http://www.e-notabene.ru/pr/article_257.html

9. Акопов Г.Л. Интернет-модернизация политической системы-базис для формирования информационного общества // NB: Проблемы общества и политики.-2012.-2.-C. 55-63. DOI: 10.7256/2306-0158.2012.2.180. URL: http://www.e-notabene.ru/pr/article_18o.html 


\section{References (transliteration):}

1. Lapkina N.A. Sotsial'nyi potentsial internet-resursov v diskurse etnichnosti // Uchenye zapiski Petrozavodskogo gosudarstvennogo universiteta. Ser. "Obshchestvennye i gumanitarnye nauki". № 3 (116). Mai, 2011. S. 73-76.

2. N.A. Lapkina Metodiki analiza diskursa etnichnosti v global'noi seti // Istoricheskie, filosofskie, politicheskie i yuridicheskie nauki, kul'turologiya i iskusstvovedenie. Voprosy teorii i praktiki, № 4 (10) 2011. Chast' 1, S. 92-96

3. Yarlykapov A.A. Sovremennyi Dagestan: aktual'nye etnopoliticheskie i etnokonfessional'nye problemy // NB: Problemy obshchestva i politiki.-2012.-3.-C. 130-153. DOI: 10.7256/23060158.2012.3.257. URL: http://www.e-notabene.ru/pr/article_257.html

4. Akopov G.L. Internet-modernizatsiya politicheskoi sistemy-bazis dlya formirovaniya informa tsionnogo obshchestva // NB: Problemy obshchestva i politiki.-2012.-2.-C. 55-63. DOI: 10.7256/2306-0158.2012.2.180. URL: http://www.e-notabene.ru/pr/article_18o.html 